Acta horticulturae et regiotecturae 2

Nitra, Slovaca Universitas Agriculturae Nitriae, 2014, p. 52-59

\title{
LAND USE DATASET COLLECTION AND PUBLICATION BASED ON LUCAS AND HILUCS
}

\author{
Marcel KLIMENT,*1 Jakub KOČICA, ${ }^{1}$ Tomáš KLIMENT² \\ 'Slovak University of Agriculture in Nitra, Slovak Republic \\ ${ }^{2}$ National Research Council of Italy, Italy
}

\begin{abstract}
Spatial data have become very important phenomena within the last decade in Europe due to a strong support from the political spectrum with regard to related legislation and resulting in financial support to several research, educational, and enlargement projects. INSPIRE (Infrastructure for Spatial Information in the European Community) Directive indeed defines the principles for the harmonization of spatial data infrastructure in the European community, including Land Use and Land Cover data themes. INSPIRE defines a methodology on how to transform datasets to common data models, but it does not cover the process of data collection and update, because it is out of its scope. Evaluation of the Land Use dataset derived from remote sensing products complemented by fieldworks has been realized since 2006 by Eurostat within the LUCAS (Land Use and Cover Area frame Survey) project. The work presented in this paper follows the LUCAS fieldwork methodology, which was applied during the fieldwork in July 2014 in the City of Zagreb (Croatia), to use at the local (municipal) geoportal level. The surveying groups collected point features with the following data type attributes: Land Use codes defined by HILUCS (Hierarchical INSPIRE Land Use Classification System) and optional Land Cover codes defined by LUCAS classification. In addition, photographs representing the observed areas were collected by cameras embedded in the mobile GIS platforms. An update of original topological layer was performed and Web GIS components for sharing the newly developed datasets were implemented. The results presented provide a suitable proposal for fieldworks methodology and updates of a land use database in line with the INSPIRE directive applicable at a local spatial data infrastructure level.
\end{abstract}

Keywords: Land Use, INSPIRE, LUCAS, Web GIS, Local SDI

Urban planning is a complex task requiring multidimensional urban information (spatial, social, economic, etc.). The need for assistance in performing urban planning tasks has led to the rapid development of urban information systems, especially "e-Planning" systems, with the support of government policy and emerging information and communication technologies (Wang et al., 2007). One of the important datasets required for local planning is data about the land: land use by type - residential, commercial, industrial, recreational and open space, institutional, etc.; by density / intensity; ownership; land supply/demand; development potential (Nedovic-Budic et al., 2004). Land use (LU) and Land cover are core information layers for a variety of scientific activities as well as administrative tasks (e.g. hydrological modelling, climate models, LU planning, integrated land management, agricultural crop mapping) usually covered by state public agencies. In the last decades, the LU coverage change has become an additional irreplaceable observation feature not only in Europe, but across the whole globe. LU and land cover mapping products are mandatory baseline datasets usually required for large areas with different levels of detail. Since, they should be provided in an interoperable way by applying harmonized, reliable, effective and efficient methods. To ensure this, space and aero remote sensing techniques integrated with field information collected by citizen sensors have been gaining ground against large scale statistical surveys based on in-situ observations (Manakos and Braun, 2014). Interoperability bridges the heterogeneity of datasets by transformation; a process, which switches from one state to another. These procedures can be expressed by a simple change, but terms as converting, remodelling, reshaping are also used in the scientific terminology for transformation. In an established 'Spatial Data Infrastructure', SDI, a data provider publishes the data according agreed standardised data presentation to achieve the interoperability. The theoretical approach in an SDI for interoperability should be conducted, to keep the original data structure and publish data via transformation procedures with predefined mapping rules following the target specification (Granell et al., 2009).

The Directive 2007/2/EC establishing the Infrastructure for Spatial Information in the European Community (INSPIRE) entered into force on the 15th of May 2007. The main objective of the Directive is to establish the infrastructure for spatial information in Europe to support Community environmental policies. The INSPIRE addresses 34 spatial data themes organized in three groups reflecting different levels of harmonization efforts expected and a staged phasing (Cooper et al., 2011). Groups I and II focus on reference data, while Group III focuses on data for environmental analysis and impact assessment, including the LU data theme defined as territory characterised according to its current and future planned functional dimension or socio-economic purpose (e.g. residential, industrial, commercial, agricultural, forestry, recreational). The hierarchical INSPIRE Land Use Classification System (HILUCS) is a multi-level classification system developed for application to the existing and planned land use to ensure that the spatial data infrastructures of the Member States are compatible and usable in the European community and 
transboundary context, the Directive requires that common Implementing Rules (IR) or components adopted in a number of specific areas (Metadata, Data Specifications, Network Services, Data and Service Sharing and Monitoring and Reporting) (Cetl et al., 2009). The European statistical office Eurostat carries out a survey on the state and the dynamics of changes in LU and land cover in the European Union called the LUCAS survey. The aim of the LUCAS survey is to gather harmonised data on land use/cover and their changes over time. In addition, the survey provides territorial information facilitating the analysis of the interactions between agriculture, environment and countryside. The surveys are done every three years. The LUCAS surveys are carried out in-situ; this means that observations are made and registered on the ground all over the EU. From LUCAS survey, 3 types of information are obtained: micro data (land cover, land use and environmental parameters associated to the single surveyed points, including transect information), point and landscape photos in the four cardinal directions and statistical tables with aggregated results by land cover, land use at geographical level. The land cover and the visible land use are classified according to the harmonized LUCAS land cover and land use nomenclatures, which is similar with INSPIRE's HILUCS nomenclature. The latest LUCAS survey (2012) covers all 27 EU countries. LUCAS points belong to the intersections of a $2 \mathrm{~km}$ grid that includes around 1 million points all over the EU. During the LUCAS 2012 survey, a sample of 270,000 of these points was visited on the spot by 750 field surveyors (Eurostat, 2013).

The manuscript describes the application of LUCAS observation methodology concepts and INSPIRE existing land use categories definitions. The practical exercise was carried out at the local SDI level during the summer GIS school held in Zagreb (July 2014). The work performed consisted in LU dataset collection, processing and publication. The material and methods chapter defines the study area details and reference input datasets provided by the city of Zagreb. Information about the methodology used during the fieldworks, software used for data processing and publication is described further on. The results chapter reports basic statistics and final products produced by the project. Individual problems discovered during the newly developed dataset life cycle are discussed and conclusions are drawn.

\section{Material and methods}

\section{Study area}

The central part of the city of Zagreb was chosen as the territory of the LU dataset definition, with the Sava River as a natural boundary suitable for the allocation of survey zones. The selected area of Zagreb was divided into six survey zones (Figure 1) with various character of land usage. Briefly, Zone 1 is characterized by its recreational and sporting facilities. Zone 2 is mainly residential. In Zone 3, there are administrative and commercial headquarters, with a distinctive urban character. Zone 4 has a varied distribution of agricultural, industrial and natural environments. Zones 5 and 6 are characterized by residentialcommercial use with high amount of recreational areas (Figure 2).

The reference input spatial data were represented by a topographical dataset provided by the city of Zagreb, created as a product of remote sensing. The total area of observation was 1,825.4 hectares. The overall amount of polygon features that were present in the reference topographic dataset was more than 11,000. Original LU classification available in input dataset contained 23 categories. The basic statistics of the input dataset is reported in Table 1.

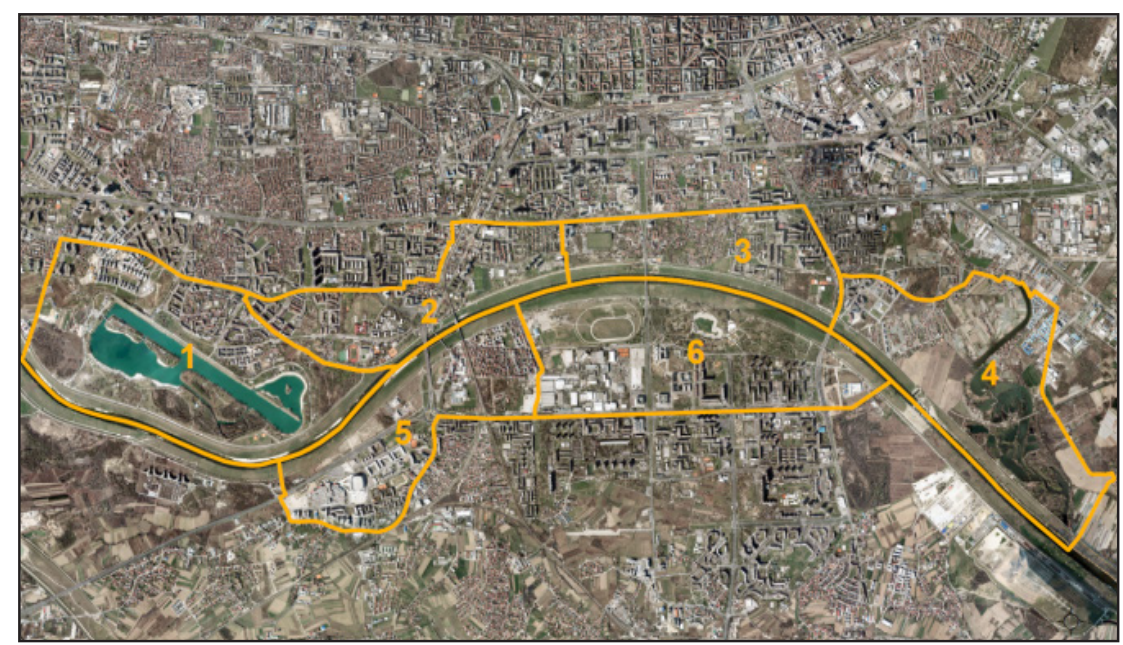

Figure 1 Study area - digital orthophoto with surveying zones boundary definition

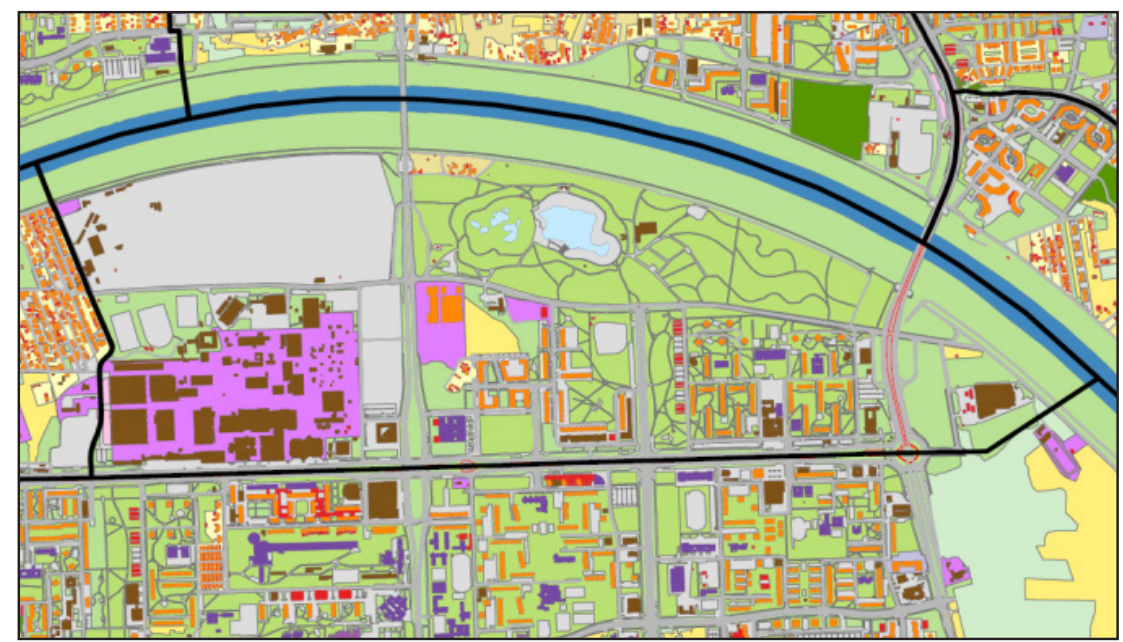

Figure 2 Study area - Zone 6 input topographic database 
Table 1 Land use categories and related spatial objects available in reference topographic dataset

\begin{tabular}{|c|c|c|c|c|}
\hline Original nomenclature & Area in ha & Part from whole area in \% & Feature count & $\varnothing$ area of feature in ha \\
\hline Residential and combined objects & 74.76 & 4.10 & 3751 & 0.02 \\
\hline Public objects & 13.48 & 0.74 & 213 & 0.06 \\
\hline Economical objects & 45.87 & 2.51 & 844 & 0.05 \\
\hline Cultural objects & 0.01 & 0.00 & 1 & 0.01 \\
\hline Religious objects & 0.43 & 0.02 & 12 & 0.04 \\
\hline Other objects & 15.7 & 0.86 & 2543 & 0.01 \\
\hline Road transportation & 121.02 & 6.63 & 449 & 0.27 \\
\hline Railway transportation & 3.2 & 0.18 & 6 & 0.53 \\
\hline Public transportation & 6.07 & 0.33 & 29 & 0.21 \\
\hline Arable land & 119.44 & 6.54 & 74 & 1.61 \\
\hline Grassland & 416.09 & 22.79 & 1349 & 0.31 \\
\hline Fruit plants and vineyard & 17.75 & 0.97 & 44 & 0.40 \\
\hline Park & 229.13 & 12.55 & 654 & 0.35 \\
\hline Forests & 98.97 & 5.42 & 20 & 4.95 \\
\hline Shrubland & 40.72 & 2.23 & 43 & 0.95 \\
\hline Abandoned area & 3.69 & 0.20 & 6 & 0.62 \\
\hline Public build up area & 246.15 & 13.48 & 689 & 0.36 \\
\hline Economic build up area & 47.13 & 2.58 & 30 & 1.57 \\
\hline Transportation build up area & 0.17 & 0.01 & 1 & 0.17 \\
\hline Courtyard & 117.46 & 6.43 & 306 & 0.38 \\
\hline Areas under construction & 6.27 & 0.34 & 11 & 0.57 \\
\hline Water streams & 84.05 & 4.60 & 13 & 6.47 \\
\hline Backwater & 117.84 & 6.46 & 23 & 5.12 \\
\hline Total & 1825.4 & 100.00 & 11111 & 0.16 \\
\hline
\end{tabular}

Data collection - field works LU mapping has been already a subject of many scientific works, always depending on the context of use. For instance, agricultural land can be used for land consolidation projects and its impact on the visual

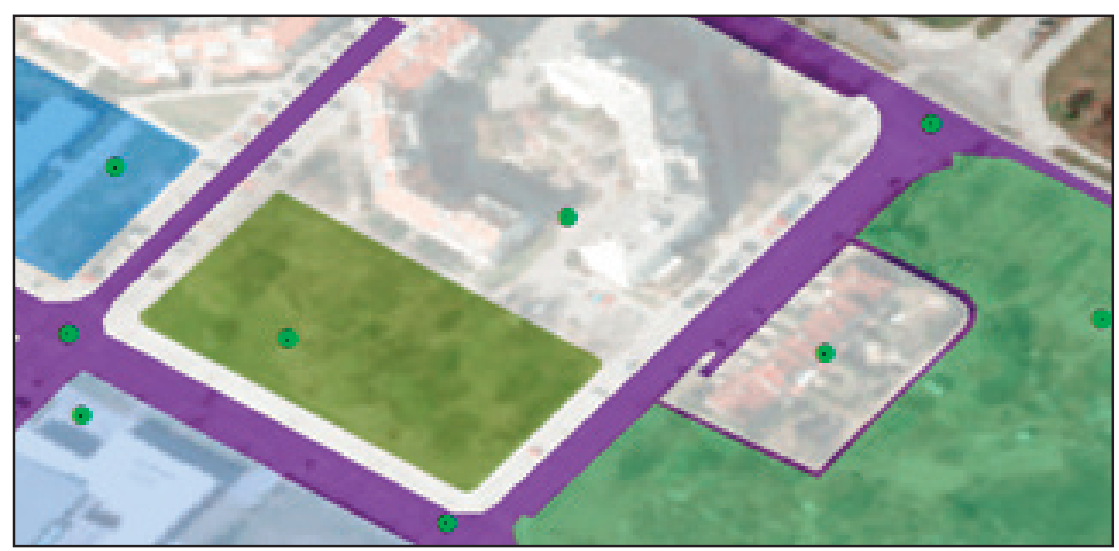

Figure 3 Example of a suitable position of observed points scenery of a landscape (Muchová and Petrovič, 2014), for soil bonitation and determination of soil prices (Stred'anská et al., 2013), or for soil erosion determination and modelling (Lackóová et al., 2013; Urban et al., 2013). However, mapping in urban spaces is applied in a different way, e.g. remote sensing data are more difficult to be used, and additional field works are required.

Mobile GIS devices Trimble Juno 3B with integrated, highly sensitive GPS receiver with Real-time measurement accuracy 2-5 meters and integrated 5 Mpix camera and pre-installed mobile GIS software ESRI ArcPad were used for the field works. Custom form for creating and editing the feature attributes was developed with ArcPad Studio (Rusmore, 2002) utility and attached to the dataset observation points. Attributes such as HILUCS (Benner et al., 2013) LU and LUCAS LC codes (Gallego et al., 2008) together with cardinal direction photographs were implemented into the data model for field observations dataset. Surveying groups were taking observation for each accessible 


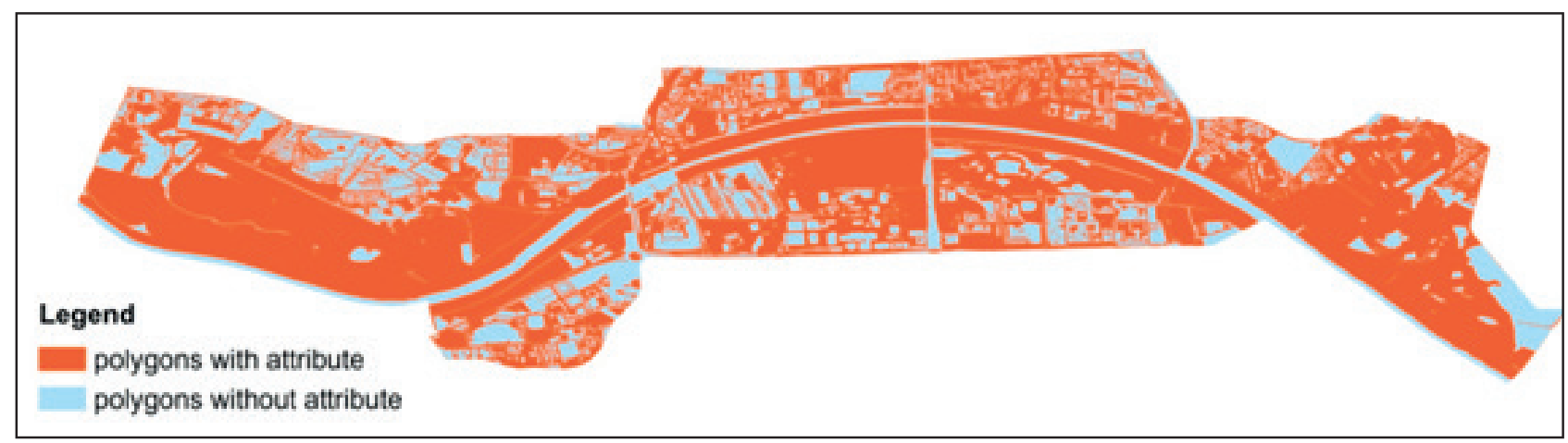

Figure $4 \quad$ Map of polygons with attributes directly transposed from observed points

polygon present in the reference input topographic dataset (Figure 3); evaluating possible aggregation of the topographical features into a new LU feature based on HILUCS categories definitions and adapts the observation point for this purpose. For each observed point, a surveyor took one photograph for each cardinal orientation. The photographs aimed at capturing the observed areas in the best possible way.

\section{Data processing}

The main tool used for the data processing was GIS client Quantum GIS (QGIS) as a most advanced open source GIS editor, described by Tsou and Smith (2011). QGIS is freely downloadable and is distributed with open code with many available custom modules for integration, topological cleaning and processing of data of various types. To perform an update of the topological dataset with the newly collected LU code attributes, it has been necessary to match the observed characteristics from the survey points and merge it with the source polygon features. Taking the attributes of different layers into the target dataset was realized by joining the attributes of features by location. Join algorithm is based on the rule that the polygon which does not contain a point takes an attribute from the nearest point. But the rule of taking attributes based on the distance weight is not in the relationship with distribution of LU in the real world. For this reason, the joining algorithm from the observed points was restricted only for the polygons which contained a specific point. Before this process, each of the six working groups verified the accuracy of observed points and additionally adjusted or discarded the points from the next data processing.
Topology checking functionality provided by a custom QGIS module was used to verify the correctness of topological relation among features according to predefined rules.

\section{Data publication - Web GIS}

Geospatial data were published using the following Web GIS components:

- GIS database - The underneath GIS database was implemented using PostgreSQL, which is an open source object-relational database management system (ORDBMS) with an emphasis on extensibility and standards-compliance. Additionally, it allows managing geographic objects through its extension PostGIS, which is an open source software product freely available to download and install. PostGIS adds extra data types (geometry, geography and others) to the PostgreSQL database. It also adds functions, operators, and index enhancements that apply to these spatial data types. These additional functions, operators, index bindings and types augment the power of the core PostgreSQL DBMS, making it a

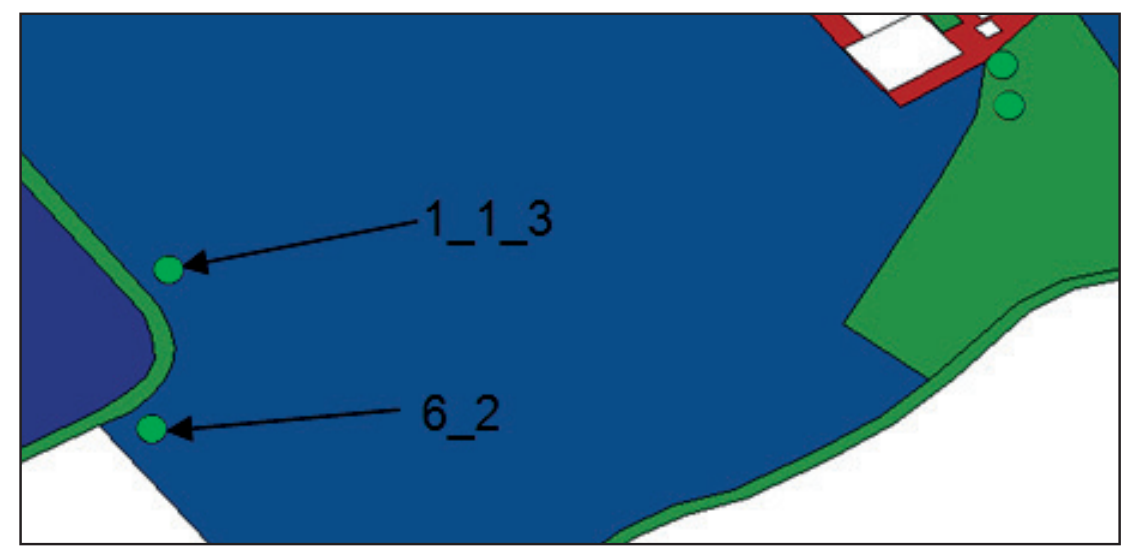

Figure 5 Surveying errors - Duplicated observed points with different HILUCS attribute values fast, feature-plenty, and robust GIS database management system (Obe, 2011).

- Web GIS server - In order to accomplish the requirements for a Web GIS server component, we have used GeoServer open source software, which is designed to ensure interoperability by publishing data from any major spatial data source using open standards (Giannecchini and Aime, 2013).

- Web GIS client - Mapshup is a Web GIS client based on standard web technologies (i.e. JavaScript/CSS/ HTML). The user interface is designed to work both on desktop and portable touchscreen devices through a standard web browser. It is able to connect to a large range of web services including: OpenStreetMap/ Bing/Google maps as base maps layers, OGC services (WMS, WFS, (SW and WPS), Google Earth plugin, Google Streetview, Google Elevation, Flickr API, YouTube API, Wikipedia API, Geonames, RSS and Atom feeds, and other services. Out of the box functionalities, the following are included: auto-detection of data 
Table 2 Distribution of HILUCS Land Use categories in the final dataset

\begin{tabular}{|c|c|c|c|c|}
\hline HILUCS code & Nomenclature & Area in ha & Feature count & $\varnothing$ feature area in ha \\
\hline 1_1_1 & Commercial agricultural production & 39.37 & 7 & 5.62 \\
\hline 1_1_2 & Farming infrastructure & 4.51 & 2 & 2.25 \\
\hline 1_1_3 & Agricultural production for own consumption & 58.48 & 53 & 1.10 \\
\hline 1_2_1 & Forestry based on short rotation & 1.07 & 1 & 1.07 \\
\hline 1_2_3 & Forestry based on continuous cover & 0.71 & 1 & 0.71 \\
\hline 2_1_1 & Textile manufacturing & 2.40 & 1 & 2.40 \\
\hline 2_1_6 & Manufacturing basic metals & 0.68 & 1 & 0.68 \\
\hline 2_1_7 & Manufacturing of non-metal products & 0.34 & 1 & 0.34 \\
\hline 2_3_1 & Food and beverage manufacturing & 0.64 & 1 & 0.64 \\
\hline $2 \_4$ & Energy production & 24.38 & 4 & 6.09 \\
\hline 2_4_2 & Energy production based on fossil fuel & 0.05 & 1 & 0.05 \\
\hline 3_1_1 & Accommodation and food services & 26.91 & 30 & 0.90 \\
\hline 3_1_3 & Other commercial services & 6.43 & 36 & 0.18 \\
\hline 3_1_4 & Financial and insurance services & 38.22 & 10 & 3.82 \\
\hline 3_2_1 & Professional services & 2.23 & 3 & 0.74 \\
\hline 3_2_2 & Information and communication & 1.45 & 1 & 1.45 \\
\hline 3_2_3 & Administrative services & 10.36 & 4 & 2.59 \\
\hline 3_2_4 & Other financial services & 0.24 & 1 & 0.24 \\
\hline 3_2_5 & Public administration & 0.05 & 1 & 0.05 \\
\hline 3_3_1 & Education & 1.35 & 4 & 0.34 \\
\hline 3_3_2 & Health and social services & 18.08 & 27 & 0.67 \\
\hline 3_3_3 & Religious services & 1.08 & 5 & 0.22 \\
\hline 3_3_4 & Other public services & 1.69 & 6 & 0.28 \\
\hline 3_3_5 & Cultural services & 0.06 & 2 & 0.03 \\
\hline 3_4_1 & Sports infrastructure & 1.79 & 2 & 0.89 \\
\hline 3_4_3 & Open air recreational areas & 115.68 & 78 & 1.48 \\
\hline 3_4_4 & Other recreational services & 226.90 & 332 & 0.68 \\
\hline 3_4_5 & Other services & 4.13 & 7 & 0.59 \\
\hline 3_5 & Road transportation & 9.77 & 72 & 0.14 \\
\hline 4_1_1 & Railway transportation & 204.07 & 222 & 0.92 \\
\hline 4_1_2 & Water transportation & 6.36 & 19 & 0.33 \\
\hline 4_1_5 & Other transport networks & 17.96 & 62 & 0.29 \\
\hline 4_2 & Logistical and storage services & 19.16 & 7 & 2.74 \\
\hline 4_3_1 & Electricity, gas and thermal power distribution & 0.70 & 6 & 0.12 \\
\hline 4_3_3 & Waste treatment & 0.58 & 1 & 0.58 \\
\hline 4_3_4 & Other utilities & 0.03 & 12 & 0.00 \\
\hline 5_1 & Permanent residential use & 194.29 & 249 & 0.78 \\
\hline 5_2 & Residential use with other uses & 118.80 & 135 & 0.88 \\
\hline $5 \_3$ & Other residential use & 0.48 & 1 & 0.48 \\
\hline $6 \_1$ & Transitional areas & 13.90 & 6 & 2.32 \\
\hline $6 \_2$ & Abandoned areas & 17.61 & 22 & 0.80 \\
\hline 6_3_1 & Land areas not in economic use & 433.21 & 269 & 1.61 \\
\hline 6_3_2 & Water areas not in economic use & 198.54 & 13 & 15.27 \\
\hline $6 \_5$ & Areas without any specified planned use & 0.76 & 3 & 0.25 \\
\hline \multicolumn{2}{|l|}{ Total } & 1825.53 & 1721 & 1.06 \\
\hline
\end{tabular}


layers through Drag \& Drop of files and/or URL addresses to the map, 2D and 3D support, content creation, context saving and sharing through email/Facebook/twitter. The user interface is "map centric" by default. All information is displayed within the map which represents $100 \%$ of the view except for the top header bar which may contain generic actions as a free text search input form, the map backgrounds switcher, the share button, the help button, the login information. The user interface is designed to be easy to use on touch devices. As a consequence, each functionality is accessible through one single touch and "hidden" menu are avoided as possible, making the user experience very intuitive (Gasperi et al., 2013).

\section{Results and discussion}

The fieldwork lasted four days and resulted in the total number of 1,755 observation points collected by six working groups. Initial verification of observations during the data processing phase filtered a set of 132 points that were not used for the further classification due multiple and outlier measurement.

The results of an automatic attribute joining by location of observations with reference topographic dataset, represented 1,099 features $(9.89 \%$ of the source dataset feature count). The total area classified by HILUCS codes covered 1,259.12 hectares (68.98\% of the entire area of interest) (Figure 4).

Additionally, 566.4 hectares of Land Use (31.02\% of features) were determined manually. In the source topographic dataset reference topographic dataset, the average area of available land use features represented 0.16 hectares for land use categories, which after data processing became 1.06 hectares. The number of objects was more than 11,000 , which was processed to 1,721 what constitutes about 6.5 -fold reduction. The representation of HILUCS Land Use categories classification in final dataset is presented in Table 2. Compared with the initial classification (Table 1), there is apparent higher resolution of the INSPIRE Land Use classification in the same areas, but with less polygon

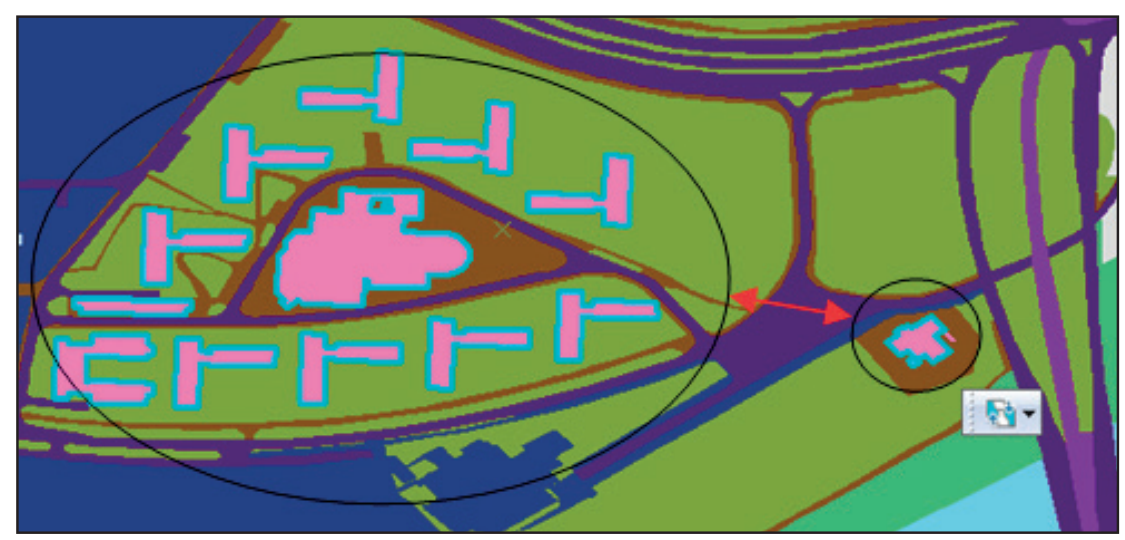

Figure 6 Merging features without the relationship in real world

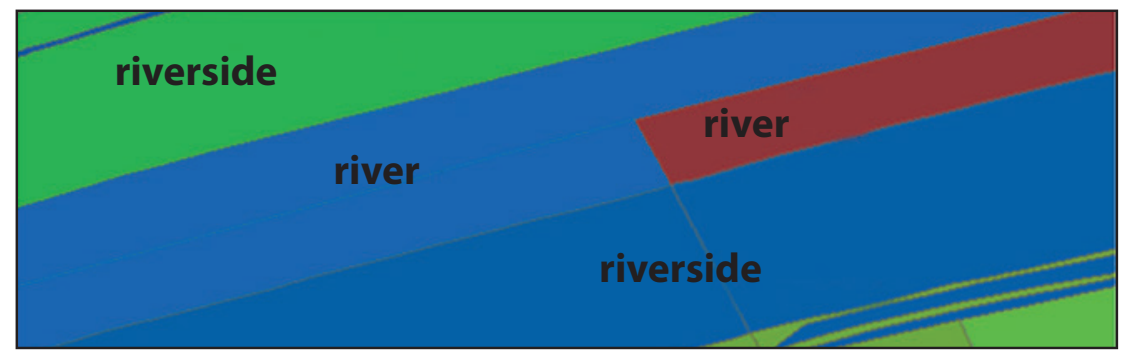

Figure 7 Assigning different categories of Land Use for identical objects by surveying groups

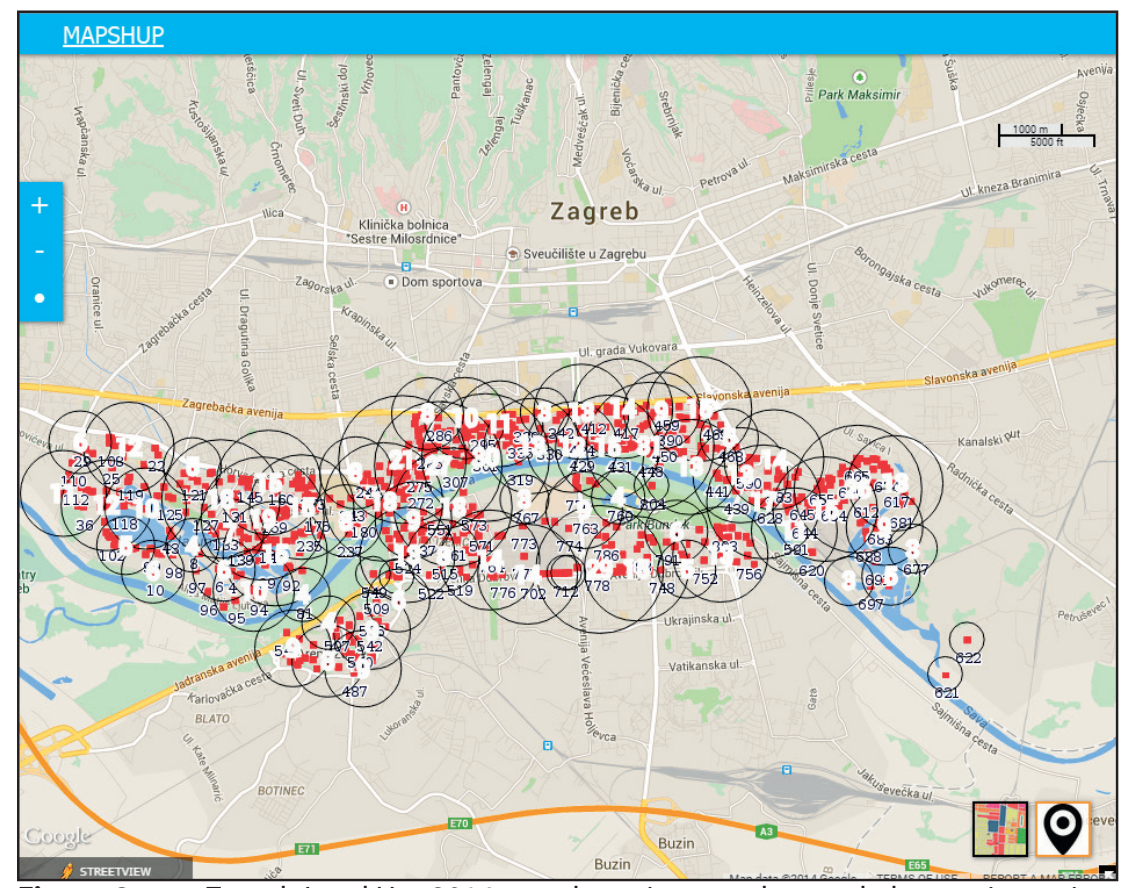

Figure 8 Zagreb Land Use 2014 mapshup viewer - clustered observation points

count and more homogenous representation.

In comparison with the LUCAS methodology reported in Gallego et al. (2008), the density of survey points was not predefined. Only a recommendation was made to observe each polygon available from the original topographic dataset or aggregation of a group of polygons identified by observation point with photographs taken at the site. The observation depended on variability of land use distribution and density as well as accessibility of polygons. During the data processing phase, several problems 


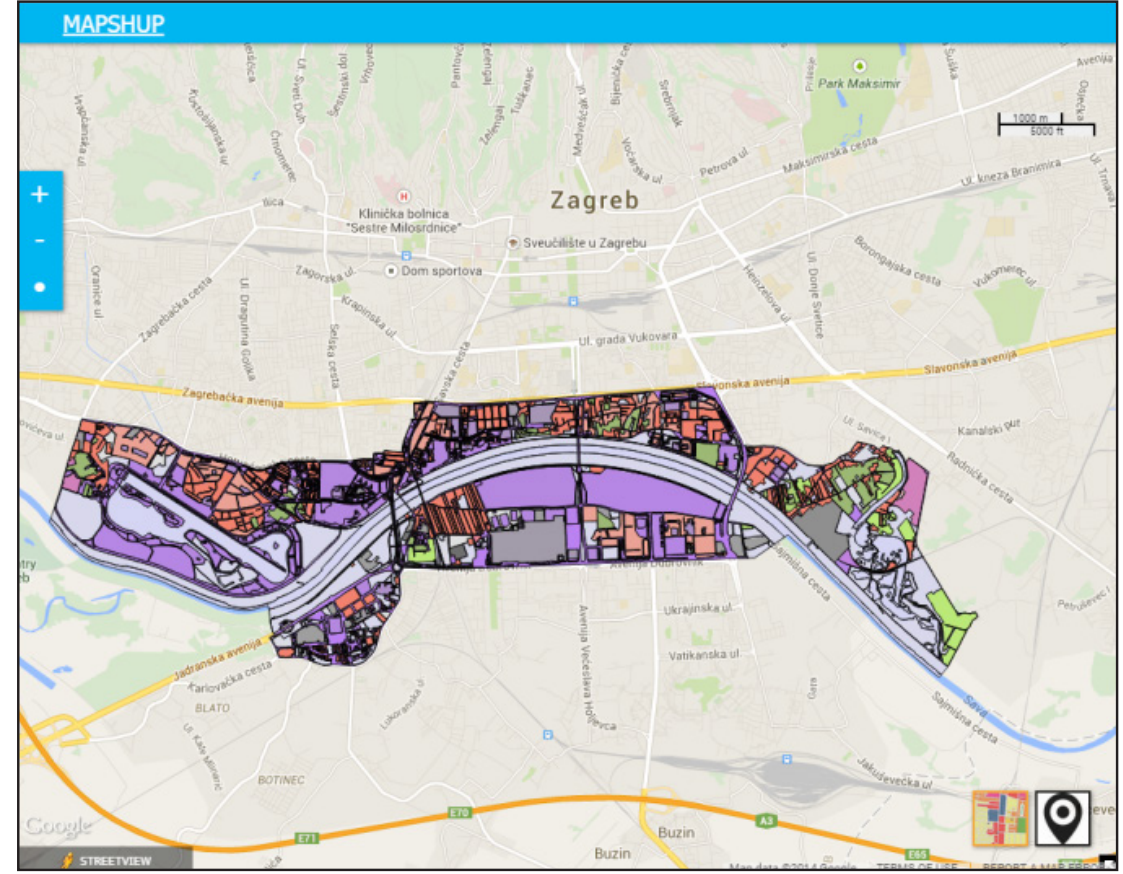

Figure 9 Zagreb Land Use 2014 mapshup viewer - LU dataset polygons

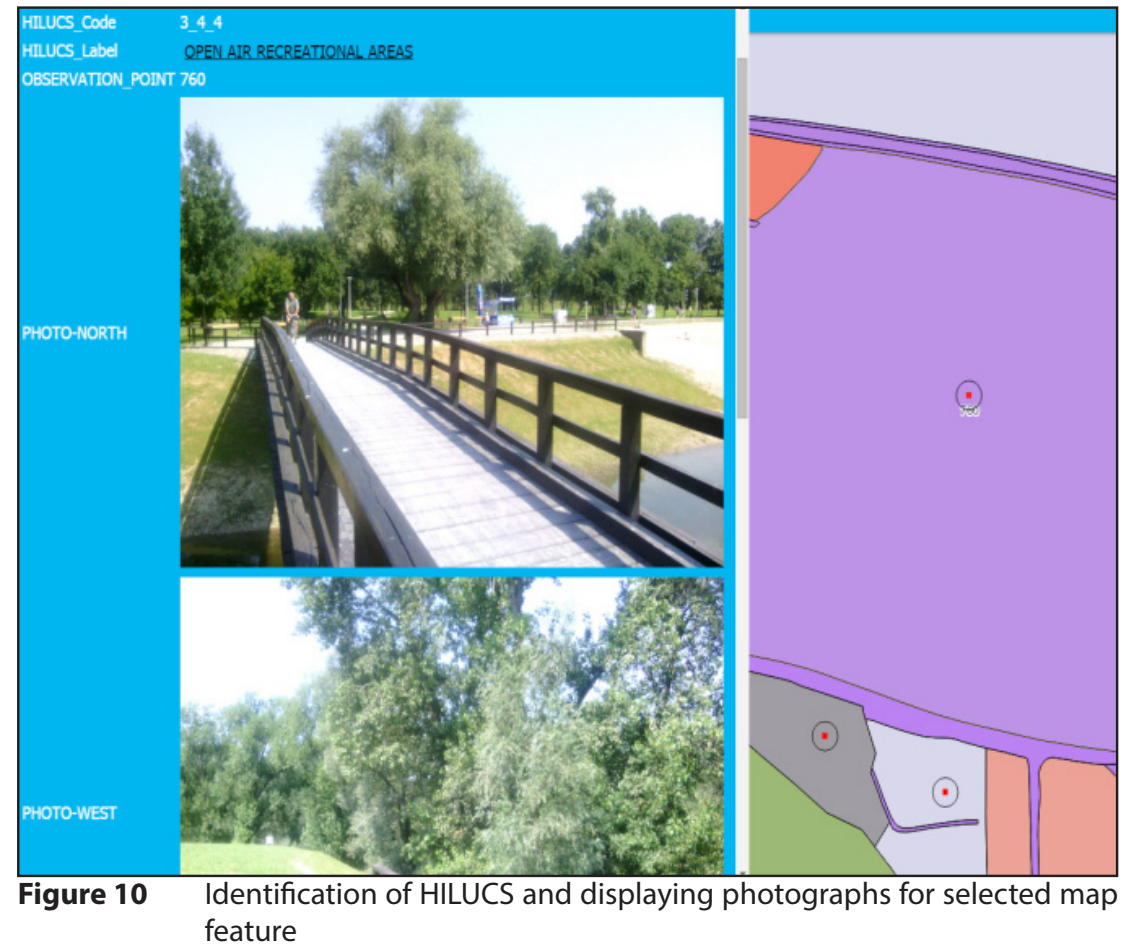

were identified. Wrong or mismatching HILUCS attributes assignment for a single polygon (Figure 5). This may have been caused due measurement errors for neighbouring polygon or various land use interpretations by surveying groups. Furthermore, it is important to avoid duplication of observed points in a single polygon and redundancy of points in potential aggregation areas (Figure 5).
Multiple topological errors were detected in the initial version of the merged LU dataset. Most errors were inherited from the input topological dataset. Obviously, for the total area, the manual corrections would have been very difficult to manage, thus in order to make this process more effective, the LU dataset has been converted into a raster data model with the pixel resolution of $0.15 \mathrm{~m}$, which ensured that the original geometry has been preserved for the following vectorization. By automatic vectorization, a new layer has been created, with its topology independent from the original data. As a result, the numbers of topological errors have been reduced from thousands to dozens. These errors could have easily been corrected manually and the final LU dataset was prepared for publication on the web.

The products of the field works as well as the final product: Zagreb Land Use 2014 dataset were stored in the GIS database Postgres/Postgis, published on the web via Web Map Service provided by open source GIS server - GeoServer and made available for users on the Internet through open source Web GIS client mapshup (Figures 8 and 9).

Each observation point (Figure 8) and land use zone (Figure 9) map feature provides relevant attributes collected in the field and produced during the data processing phase. Each land use zone contains HILUCS code and its label, identifier of the observation point used to define HILUCS code, and the photographs taken at the point (Figure 10). HILUCS label attribute provides a link to the INSPIRE registry where the land use code definitions is provided in 23 European languages, including the Slovak and Croatian language (Figure 11).

\section{Conclusions}

By applying principles from the INSPIRE and LUCAS, we have shown how these two approaches can be used on a local SDI level in order to create a harmonized LU dataset, created from topographical and fieldwork data. These datasets are available for e-Planning and further developments on the select area of the city of Zagreb. The approach 


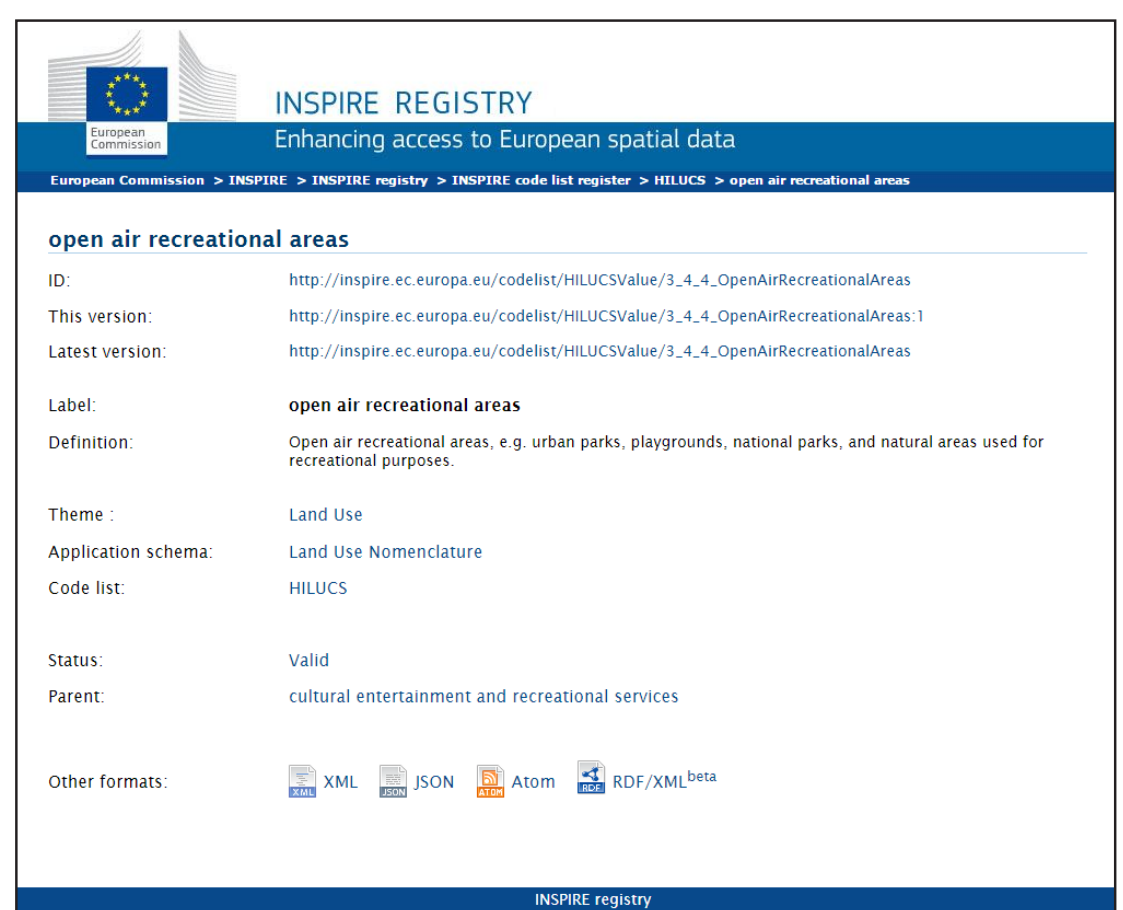

Figure 11 HILUCS category multilingual definition in the INSPIRE Registry opened from mapshup viewer for selected map feature

described in the present document is novel and could be extended to other context.

These datasets could be a starting point for future investments and extension in spatial urban planning of the city of Zagreb.

\section{References}

BENNER, J. - HÄFELE, K. H. - GEIGER, A. 2013. Transnational Planning Support by the European Geodata Infrastructure INSPIRE. Proceedings. In: REAL CORP 2013: Planning Times (M. Schrenk, V. Popovich, P. Zeile, P. Elisei) (eds.). Rome, Italy : REAL CORP, 2013, pp. 1009-1017. ISBN 978-3-9503110-4-4.

CETL, V. - ROIĆ, M. - MASTELIĆ-IVIĆ, S. 2009. Creation of an NSDI strategy - Case Study Croatia. In International Journal of Spatial Data Infrastructures Research, vol. 4, 2009. pp. 96-110. ISSN 1725-0463.

COOPER, A. K. - RAPANT, P. - HJELMAGER, J. - LAURENT, D. - IWANIAK, A. - COETZEE, S. - DÜREN, U. 2011. Extending the formal model of a spatial data infrastructure to include volunteered geographical information. In: 25th International Cartographic Conference (ICC 2011). Paris, France, 3-8 July 2011.

EUROSTAT. 2013. Methodology of the LUCAS survey. Available at http://epp. eurostat.ec.europa.eu/portal/page/portal/ lucas/methodology.

GALLEGO, J. - BAMPS, C. 2008. Using CORINE land cover and the point survey LUCAS for area estimation. In International
Journal of Applied Earth Observation and Geoinformation, vol. 10, 2008, no. 4, pp. 467-475. ISSN 0303-2434.

GASPERI, J. - PEYREGA, C. - DINOT, S. BOILEAU, Q. - MANIN, A. - HEURTEAUX, V. 2013. Web Processing Service for assisted land cover classification. In EGU General Assembly Conference Abstracts. Vienna, Austria : EGU, vol. 15, 2013, pp. 6087.

GIANNECCHINI, S. - AIME, A. 2013. GeoServer, the Open Source server for interoperable spatial data handling. In: SDI 2013 Proceedings. Croatia, Zagreb : State Geodetic Administration, Zagreb, Croatia, 2013. pp. 14-22. ISBN 978-953-293-519-6. GRANELL, C. - GOULD, M. - MANSO, M. A. - BeRNABÉ, M. A. 2009. Spatial Data Infrastructures. In: Handbook of research on Geoinformatics (Hassan a. Karimi) (ed). Hersey PA : IGI Global, 2009. pp. 36-41. ISBN 978-159-140-9960.

LACKÓOVÁ, L. - KONDRLOVÁ, E. STREĎANSKÝ, J. - URBAN, T. - STREĎANSKÁ, A. 2013. Comparison of rill erosion modelling according ULSE equation and Mitašová methodology and parameters in GIS using various crop management. In Acta scientiarum Polonorum, vol. 12, 2013, no. 3, pp. 11-19. ISSN 1644-0765.

MANAKOS, I. - BRAUN, M. 2014. Land Use and Land Cover Mapping in Europe. Practices \& Trends. In Remote Sensing and Digital Image Processing, vol. 18, 2014, pp. 437. ISBN 978-94-007-7968-6

MUCHOVÁ, Z. - PETROVIČ, F. 2014. Impact of land consolidation on the visual characteristics (scenery) of a landscape. In Journal of Central European Agriculture
(Online), vol. 15, 2014, no. 1, pp. 76-85. ISSN 1332-9049.

NEDOVIC-BUDIC, Z. - FEENEY, M. E. F. RAJABIFARD, A. - WILLIAMSON, I. 2004. Are SDls serving the needs of local planning? Case study of Victoria, Australia and Illinois, USA. In Computers, Environment and Urban Systems, vol. 28, 2004, no. 4, pp. 329-351. ISSN 0198-9715.

OBE, O. R. - HSU, S. L. 2011. PostGIS in action. New York, USA : Manning Publications Co, 2011. 520 p. ISBN 9781935182269.

RUSMORE, M. E. 2002. Teaching Advanced Field Mapping on Hand - Held Computers. In 2002 Denver Annual Meeting.

STREĎANSKÁ, A. - MUCHOVÁ, Z. - KONC, L. 2013. Bonitácia a cena pôdy v pozemkových úpravách. 1. vyd. Nitra : SPU, 2013. 228 s. ISBN 978-80-552-1129-9.

TSOU, M. H. - SMITH, J. 2011. Free and Open Source software for GIS education. In: Unpublished White Paper Prepared for the GeoTech Center. Louisville, USA : NGTCE. 18 p. Available at http://www. iapad. org/ publications/ppgis/tsou_free-GIS-foreducators-whitepaper.pdf.

URBAN, T. - LACKÓOVÁ, L. - HALÁSZOVÁ, K. - STREĎANSKÝ, J. 2013. Wind erosion in the agricultural landscape : the wind erosion equation used in GIS. $1^{\text {st }}$ ed. Kraków, Poland : Uniwersytet Rolniczy, 2013. 109 p. ISBN 978-83-60633-97-7.

VILCHES-BLÁZQUEZ, L. M. - VILLAZÓNTERRAZAS, B. - SAQUICELA, V. - DE LEÓN, A. - CORCHO, O. - GÓMEZ-PÉREZ, A. 2010. GeoLinked data and INSPIRE through an application case. In Proceedings of the $18^{\text {th }}$ SIGSPATIAL International Conference on Advances in Geographic Information Systems. New York, USA : ACM, 2010. pp. 446-449. ISBN 978-1-4503-0428-3.

WANG, H. - SONG, Y. - HAMILTON, A. CURWELL, S. 2007. Urban information integration for advanced e-Planning in Europe. In Government Information Quarterly, vol. 24, 2007, no. 4, pp. 736-754. ISSN 0740-624X.

ESRI ArcPad. http://www.esri.com/ software/arcgis/arcpad

\section{Contact address:}

Marcel Kliment, Slovak University of Agriculture in Nitra, Faculty of Horticulture and Landscape Engineering, Department of Landscape Planning and Ground Design, Hospodárska 7, 94976 Nitra, Slovakia, e-mail:marcel.kliment@uniag.sk 